\title{
Ovarian follicular population changes with the advance of the breeding season in intact and unilaterally ovariectomized ewes
}

\author{
J. J. Dufour and L. A. Guilbault \\ Agriculture Canada, Research Station, Lennoxville, Quebec, Canada JIM $1 Z 3$
}

\begin{abstract}
Summary. In ewes at the 1st, 2nd or 4th oestrous cycle after unilateral ovariectomy, the ovulation rate remained constant at 1.5 in the control (sham-operated) ewes, but increased from 1.3 to 2.0 in unilaterally ovariectomized ewes.

In control ewes, the proportion of preantral follicles declined significantly $(P<$ 0.05 ) with each oestrous cycle while the antral follicles increased as the breeding season progressed $(P<0.05)$. In contrast, after unilateral ovariectomy, the proportion of preantral and antral follicles remained constant throughout the cycles studied. The rate of atresia of antral follicles, especially those from small size classes, decreased significantly after one cycle of unilateral ovariectomy $(P<0.05)$. Larger antral follicles had a different rate of atresia as the breeding season advanced. It is concluded that unilateral ovariectomy acutely decreased the rate of atresia and maintained the withinovary equilibrium between preantral and antral follicles which otherwise would have decreased due to the depletion of preantral follicles with the advance of the breeding season.
\end{abstract}

\section{Introduction}

Dufour, Cahill \& Mauléon (1979) showed that the development of antral follicles was controlled by an hormonal mechanism characterized by a short and immediate action, while the development of preantral follicles was controlled by a long and slow hormonal mechanism. In that study, the longterm hormonal mechanism was established by comparing the remaining ovary at 70 days after unilateral ovariectomy with the one removed at surgery, and the comparison between the two ovaries was not done at the same time. Cahill \& Mauléon (1980) observed that restocking and/or depletion of preantral and antral follicles can be affected by season. It is therefore important to dissociate the long-term hormonal mechanism from time effects and this was the objective of the present study.

\section{Materials and Methods}

A group of 25 DLS ewes ( $\frac{1}{2}$ Dorset, $\frac{1}{4}$ Leicester, $\frac{1}{4}$ Suffolk) for which the average onset of the breeding season was 19 August was used in this study. Twelve ewes were assigned to serve as controls and the other 13 to be unilaterally ovariectomized at the first oestrus observed after 10 October. Laparotomy was performed under general anaesthesia using pentobarbitone sodium on Day 2 (oestrus $=$ Day 0 ) of the cycle. In ewes with unilateral ovulation, the ovary bearing the 
corpus luteum was always left, whereas in bilaterally ovulating ewes the ovary to be removed was selected at random. Control ewes were sham-operated by exposing the genital tract.

Within each group (unilaterally ovariectomized and sham-operated) ewes were assigned to 3 subgroups on the basis of the time of a second operation. On Day 2 of the 1st, 2nd or 4th cycle following the first operation (4 ewes per subgroup for the sham-operated ewes and 4, 4 and 5 ewes respectively for each cycle in the unilaterally ovariectomized ewes), a second laparotomy was performed under general anaesthesia and the remaining ovary of the unilaterally ovariectomized ewes and the two ovaries of the sham-operated ewes were then removed.

Ovulation numbers were counted at ovariectomy and the ovaries were fixed in BouinHollande's solution, serially sectioned at a thickness of $7 \mu \mathrm{m}$ and all sections were mounted and stained with Feulgen's stain.

\section{Follicular population}

The follicular population of the ovary bearing the corpus luteum in the unilaterally ovariectomized and sham-operated ewes was examined. The total number of follicles with more than 3 layers of granulosa cells was counted as described by Cahill, Mariana \& Mauléon (1979). The follicles were classified as normal or atretic using the criteria described in previous work (Dufour $e t$ $a l ., 1979)$. They were grouped as preantral or antral follicles according to the beginning of antrum formation. Appearance of the antrum was fixed at a diameter of $0.21 \mathrm{~mm}$ for this breed of sheep, using the criteria described by Cahill et al. (1979).

Preantral follicles were grouped in the two following diameter classes : $\leq 0.11 \mathrm{~mm}$ and $0 \cdot 12-0.20$ $\mathrm{mm}$. Antral follicles were classified into three diameter classes: $0.21-0.62 \mathrm{~mm}, 0.63-2.00 \mathrm{~mm}$ and 2.01-5.70 mm. In each treatment group, the number of preantral and antral follicles in each class was expressed as a percentage of the total number of follicles present in the ovary. Within each class of follicles, subclasses were also defined and the percentage of follicles in the various subclasses was calculated.

\section{Statistical methods}

Each class of follicles was analysed separately. Data were analysed by the least squares method of fitting constants (Harvey, 1960). The model included the effects of treatment (unilateral ovariectomy versus sham-operation), the number of cycles after treatment and their interaction. Significant differences between means were tested using Duncan's multiple range test when the interaction was significant. Analyses of variance on transformed percentages using arc-sine transforms did not modify the results obtained using the raw data.

\section{Results}

The ovulation rate in the 12 control ewes slaughtered 1,2 and 4 oestrous cycles after sham-operation averaged $1.5 \pm 0.3$ corpora lutea $(C L)$ at each cycle. In unilaterally-ovariectomized ewes, the mean ovulation rate was $1.3 \pm 0.3 \mathrm{CL}$ at the first oestrous cycle, $1.5 \pm 0.3$ at the second and $2.0 \pm 0.27$ at the fourth cycle.

\section{Follicular populations}

Preantral. Of all the follicles observed $41.8 \%$ were preantral. In unilaterally ovariectomized ewes, the percentage of all preantral follicles was constant during the 3 cycles studied whereas in the sham-operated ewes it decreased (Tables 1 \& 3). The interaction 'treatment by cycles' was significant $(P<0.05$; Tables $1 \& 3)$. 
Table 1. Mean percentages of pre-antral, non-atretic and atretic antral follicles 1, 2, or 4 oestrous cycles after surgery in sham-operated and unilaterally ovariectomized ewes

\begin{tabular}{|c|c|c|c|c|c|c|c|c|c|c|}
\hline \multirow{3}{*}{$\begin{array}{c}\text { No. of } \\
\text { cycles } \\
\text { after } \\
\text { surgery }\end{array}$} & \multicolumn{5}{|c|}{ Sham-operated ewes } & \multicolumn{5}{|c|}{ Unilaterally ovariectomized ewes } \\
\hline & \multirow[b]{2}{*}{$\begin{array}{l}\text { No. of } \\
\text { ewes }\end{array}$} & \multirow[b]{2}{*}{$\begin{array}{c}\text { Average } \\
\text { total no. } \\
\text { of follicles } \dagger\end{array}$} & \multicolumn{3}{|c|}{ Types of follicles $(\%)$} & \multirow[b]{2}{*}{$\begin{array}{c}\text { No. of } \\
\text { ewes }\end{array}$} & \multirow[b]{2}{*}{$\begin{array}{c}\text { Average } \\
\text { total no. } \\
\text { of follicles } \dagger\end{array}$} & \multicolumn{3}{|c|}{ Types of follicles $(\%)$} \\
\hline & & & $\begin{array}{c}\text { Pre- } \\
\text { antral }\end{array}$ & $\begin{array}{c}\text { Antral, } \\
\text { non- } \\
\text { atretic }\end{array}$ & $\begin{array}{l}\text { Antral, } \\
\text { atretic }\end{array}$ & & & $\begin{array}{c}\text { Pre- } \\
\text { antral }\end{array}$ & $\begin{array}{c}\text { Antral, } \\
\text { non- } \\
\text { atretic }\end{array}$ & $\begin{array}{l}\text { Antral, } \\
\text { atretic }\end{array}$ \\
\hline 1 & 4 & 129 & $45 \cdot 9^{\mathrm{A} *}$ & $42 \cdot 2^{\mathrm{E} *}$ & $11.9 \mathrm{~K}$ & 4 & 139 & $45 \cdot 6^{\mathrm{A}}$ & $46 \cdot 4^{\mathrm{E}}$ & $8 \cdot 0^{\mathrm{L}}$ \\
\hline 2 & 4 & 145 & $45 \cdot 5^{\mathrm{A}}$ & $44 \cdot 7^{\mathrm{E}}$ & $9 \cdot 8^{\mathrm{K}}$ & 4 & 151 & $41 \cdot 6^{A}$ & $50 \cdot 2^{\mathrm{E}}$ & $8 \cdot 2^{\mathrm{L}}$ \\
\hline 4 & 4 & 131 & $30 \cdot 3^{\mathrm{B}}$ & $59 \cdot 8^{\mathrm{F}}-\mathrm{r}-\mathrm{r} \cdot \mathrm{l}$ & $9.9^{\mathrm{K}}$ & 5 & 140 & $45 \cdot 2^{4}$ & $46 \cdot 8^{\mathrm{E}}$ & $8 \cdot 0^{\mathrm{L}}$ \\
\hline
\end{tabular}

* Significant interaction $(P<0.05)$. Duncan's Multiple Range test was used to detect different means. Treatment means with different letters (A, B; E, F and $\mathrm{K}, \mathrm{L}$ ) are significantly different $(P<0.05)$ (see Table 3 for analyses of variance).

$\dagger$ The number of pre-antral, antral non-atretic and antral atretic follicles present per ovary per ewe from which the percentages are calculated.

Table 2. Mean percentage of pre-antral follicles and of non-atretic and atretic antral follicles 1, 2 or 4 oestrous cycles after surgery in sham-operated and unilaterally ovariectomized ewes according to size classes

\begin{tabular}{|c|c|c|c|c|c|}
\hline \multirow[b]{2}{*}{ Treatment } & \multirow{2}{*}{$\begin{array}{l}\text { Types of } \\
\text { follicles }\end{array}$} & \multirow{2}{*}{$\begin{array}{l}\text { Class of } \\
\text { follicles }\end{array}$} & \multicolumn{3}{|c|}{ No. of cycles after surgery } \\
\hline & & & 1 & 2 & 4 \\
\hline \multirow[t]{8}{*}{ Sham operation } & \multirow[t]{2}{*}{ Pre-antral } & $<0 \cdot 11$ & $14 \cdot 7^{\mathrm{a}}$ & $19 \cdot 8^{\mathrm{a}}$ & $7 \cdot 3^{b}$ \\
\hline & & $0 \cdot 12-0 \cdot 20$ & $31 \cdot 2$ & $25 \cdot 7$ & $23 \cdot 0$ \\
\hline & \multirow[t]{3}{*}{ Antral, non-atretic } & $0.21-0.62$ & $36.77^{*}$ & $37 \cdot 1^{\mathrm{e}}$ & $53 \cdot 8^{\mathrm{f}}$ \\
\hline & & $0.63-2 \cdot 00$ & 3.99 & $4 \cdot 39$ & $5 \cdot 0^{9}$ \\
\hline & & $2 \cdot 01-5 \cdot 70$ & 1.6 & $3 \cdot 3$ & $1 \cdot 0$ \\
\hline & \multirow{3}{*}{ Antral, atretic } & $0.21-0.62$ & $3 \cdot 3^{\mathrm{k} *}$ & $1 \cdot 4^{\mathrm{k}}$ & $0.0^{1}$ \\
\hline & & $0.63-2.00$ & $7 \cdot 9$ & $7 \cdot 0$ & 8.8 \\
\hline & & $2 \cdot 01-5 \cdot 70$ & 0.7 & $1 \cdot 4$ & $1 \cdot 1$ \\
\hline \multirow[t]{8}{*}{ Unilateral ovariectomy } & \multirow[t]{2}{*}{ Pre-antral } & $<0.11$ & $20 \cdot 3^{a}$ & $17 \cdot 7^{\mathrm{a}}$ & $12 \cdot 7^{\mathrm{b}}$ \\
\hline & & $0 \cdot 12-0 \cdot 20$ & $25 \cdot 3$ & 23.9 & $32 \cdot 5$ \\
\hline & \multirow[t]{3}{*}{ Antral, non-atretic } & $0.21-0.62$ & $37.7 \mathrm{e}$ & $42 \cdot 1^{\mathrm{e}}$ & $37 \cdot 4^{\mathrm{e}}$ \\
\hline & & $0.63-2.00$ & $7 \cdot 2^{\mathrm{h}}$ & $5 \cdot 2^{\mathrm{h}}$ & $6 \cdot 6^{\mathrm{h}}$ \\
\hline & & $2 \cdot 01-5 \cdot 70$ & $1 \cdot 5$ & $2 \cdot 9$ & $2 \cdot 8$ \\
\hline & \multirow[t]{3}{*}{ Antral, atretic } & $0.21-0.62$ & $0 \cdot 2^{1}$ & $0 \cdot 8^{\mathrm{k}}$ & $1 \cdot 2^{\mathrm{k}}$ \\
\hline & & $0.63-2 \cdot 00$ & $7 \cdot 5$ & $5 \cdot 9$ & $6 \cdot 0$ \\
\hline & & $2 \cdot 01-5 \cdot 70$ & $0 \cdot 3$ & 1.5 & 0.8 \\
\hline
\end{tabular}

Treatment means with different letters (a, b; e, f; g, h and $k, 1$ for the class of follicles within each type) are significantly different $(P<0.05)$ (see Table 3 for analyses of variance).

* Significant interaction $(P<0 \cdot 05)$. Duncan's Multiple Range test was used to detect differences among means.

The mean percentage of preantral follicles $\leq 0.11 \mathrm{~mm}$ in diameter were lower $(P<0.05)$ at the 4 th cycle in the sham-operated and unilaterally ovariectomized ewes (Tables $2 \& 3$ ). Mean percentages were 17.5 and 18.8 at the 1 st and 2 nd cycle respectively and decreased to $10.0 \%$ at the 4th cycle $(P<0.05)$. Within this class, the $0.08-0.11 \mathrm{~mm}$ follicular subclass contributed the most to this difference.

The percentage of larger preantral follicles $(0 \cdot 12-0 \cdot 20 \mathrm{~mm})$ also changed with the number of cycles after surgery but differently in sham-operated and unilaterally ovariectomized ewes (treatment $\times$ cycles, $0.05<P<0.10$ ). In unilaterally ovariectomized ewes, the percentage of 
Table 3. Analysis of variance of the percentages of preantral and antral follicles of different classes 1,2 or 4 oestrous cycles after surgery in sham-operated and unilaterally ovariectomized ewes

\begin{tabular}{|c|c|c|c|c|c|c|c|c|c|c|c|c|}
\hline \multirow[b]{3}{*}{$\begin{array}{l}\text { Source of } \\
\text { variation }\end{array}$} & \multirow[b]{3}{*}{ d.f. } & \multicolumn{11}{|c|}{ Mean squares } \\
\hline & & \multicolumn{3}{|c|}{ Preantral } & \multicolumn{4}{|c|}{ Antral, non-atretic } & \multicolumn{4}{|c|}{ Antral, atretic } \\
\hline & & $\leq 0 \cdot 11$ & $\begin{array}{c}0 \cdot 12- \\
0 \cdot 20\end{array}$ & Total & $\begin{array}{c}0.21- \\
0.62\end{array}$ & $\begin{array}{l}0.63- \\
2.00\end{array}$ & $\begin{array}{c}2 \cdot 01- \\
5 \cdot 70\end{array}$ & Total & $\begin{array}{l}0.21- \\
0.62\end{array}$ & $\begin{array}{c}0 \cdot 63- \\
2 \cdot 00\end{array}$ & $\begin{array}{c}2 \cdot 01- \\
5 \cdot 70\end{array}$ & Total \\
\hline $\begin{array}{l}\text { Unilateral } \\
\text { ovariectomy } \\
\text { versus } \\
\text { shamn-operation }\end{array}$ & 1 & $53 \cdot 6$ & $2 \cdot 1$ & $39 \cdot 4$ & $72 \cdot 9$ & $23 \cdot 6^{*}$ & $1 \cdot 1$ & $76 \cdot 6$ & $4 \cdot 2^{*}$ & $12 \cdot 5$ & $0 \cdot 3$ & $37 \cdot 4^{*}$ \\
\hline $\begin{array}{l}\text { No. of oestrous } \\
\text { cycles after } \\
\text { surgery }\end{array}$ & 2 & $191 \cdot 7^{*}$ & $28 \cdot 5$ & $193 \cdot 6^{*}$ & $158 \cdot 9^{*}$ & $2 \cdot 6$ & $5 \cdot 3$ & $145 \cdot 2 \dagger$ & $5 \cdot 3^{*}$ & $3 \cdot 4$ & $3 \cdot 7 \dagger$ & $2 \cdot 5$ \\
\hline $\begin{array}{l}\text { Unilateral } \\
\text { ovariectomy } \\
\text { versus } \\
\text { sham-operation } \\
\quad \times \\
\text { No. of oestrous } \\
\text { cycles after } \\
\text { surgery }\end{array}$ & 2 & $38 \cdot 8$ & $135 \cdot 2 \dagger$ & $269 \cdot 2^{*}$ & $227 \cdot 3^{*}$ & $2 \cdot 9$ & $3 \cdot 3$ & $211 \cdot 9^{*}$ & $10 \cdot 5^{*}$ & $3 \cdot 5$ & $0 \cdot 2$ & $2 \cdot 9$ \\
\hline Error & 19 & $30 \cdot 9$ & $45 \cdot 3$ & $56 \cdot 2$ & $43 \cdot 0$ & 4.9 & $2 \cdot 0$ & $50 \cdot 2$ & 0.71 & 7.0 & 0.7 & 8.5 \\
\hline
\end{tabular}

follicles in this class increased from a mean value of $24.5 \%$ at the 1 st and 2 nd cycle to $32.5 \%$ at the 4 th cycle. In contrast, in sham-operated ewes, the percentage of follicles decreased progressively between the 1 st and the 4 th cycle. The $0.12-0.14$ and the $0 \cdot 15-0 \cdot 20$ follicular subclasses making up this class did not contribute individually to this difference.

Antral. The percentage of antral follicles (non-atretic + atretic) of all classes (Table 1) was constant through the 3 cycles studied in the unilaterally ovariectomized ewes but increased significantly from a mean value of $54.2 \%$ at the 1 st and 2 nd cycle to $69.6 \%$ at the 4 th cycle in the sham-operated ewes (treatment $\times$ cycles; $P<0.05$; Tables $1 \& 3$ ). The follicles of $0.21-0.62 \mathrm{~mm}$ diameter constituted the major proportion of the non-atretic antral follicles, but the changes with cycle differed in the sham-operated and unilaterally ovariectomized ewes (treatment $\times$ cycle; $P<$ 0.05 ; Table 2). In sham-operated ewes, the percentage of follicles was increased to $53.8 \%$ at the 4 th cycle, but remained constant at $37 \%$ for all three cycles in unilaterally ovariectomized ewes. Within this class, the $0.21-0.35 \mathrm{~mm}$ and $0.36-0.62 \mathrm{~mm}$ subclass follicles contributed significantly to the trend differences observed between treatment groups.

The percentage of the second largest class of non-atretic antral follicles $(0.63-2.00 \mathrm{~mm}$ in diameter) was two percentage points higher in unilaterally ovariectomized than in sham-operated ewes during the 3 cycles studied $(P<0.05)$. Within this class, the $0.63-1.11 \mathrm{~mm}$ subclass follicles contributed the most to this difference.

The third size class of non-atretic antral follicles $(2 \cdot 01-5.70 \mathrm{~mm}$ in diameter) was the smallest and no effects of treatment or cycle were observed.

Atretic. Follicles with more than 4 pycnotic bodies were observed only in antral follicles. The total number of atretic follicles averaged $9.3 \%$ of the total follicular population studied (Table 1). At the 1st, 2nd and 4th cycle after surgery, the percentage of atretic follicles of the smallest class of antral follicles $(0.21-0.62 \mathrm{~mm})$ decreased in the sham-operated group and was lower at the 1st cycle in the unilaterally ovariectomized animals (Table 2) (treatment $\times$ cycle; $P<0.05$, Table 3 ). Follicles of the $0 \cdot 21-0.35 \mathrm{~mm}$ and $0.36-0.62 \mathrm{~mm}$ size subclass contributed equally to this difference. 
The major proportion of atretic follicles was found in the second class of antral follicles (5.9$8.8 \%$, but the percentages of follicles that were atretic remained unchanged by treatment or cycle.

In the third class of antral follicles $(2 \cdot 01-5.70 \mathrm{~mm})$ the amount of atresia was not influenced by unilateral ovariectomy, but there was a tendency for the numbers of atretic follicles to be influenced by cycles $(0.05<P<0.10$; Table 2$)$. It was $0.5,1.4$ and $0.9 \%$ for the ewes studied after 1,2 and 4 cycles respectively. However, when follicles of this class were subdivided in subclasses, follicles with a diameter between 2.01 and $3.55 \mathrm{~mm}$ were significantly influenced by cycles $(P<0.05)$.

\section{Discussion}

After unilateral ovariectomy, ovulation rate remained unchanged at the first occurring oestrus. This is in agreement with the results of Findlay \& Cumming (1977) who demonstrated that the ovulation rate was fully restored at the next oestrus when the interval between unilateral ovariectomy and the next expected oestrus was at least 4 days. Results of the present experiment suggest that short-term alterations in the population of antral follicles might contribute to the early compensation in ovulation rate observed in the unilaterally ovariectomized ewes. First, there was an immediate decrease in the rate of atresia at the next cycle, mainly in the smallest class of antral follicles $(0.21-0.62 \mathrm{~mm})$ which included the highest proportion of follicles. Second, the percentage of non-atretic antral follicles of the second largest size class $(0.63-2.00 \mathrm{~mm})$ was higher in the unilaterally ovariectomized ewes throughout the period studied. This rapid effect of unilateral ovariectomy, most probably mediated by the acute rise in gonadotrophins that occurs between 5 and $12 \mathrm{~h}$ after surgery (Findlay \& Cumming, 1977), supports previous observations that antral follicles were under a short and immediate control of gonadotrophin (Dufour et al., 1979). Control of this type might modulate the dynamics of antral follicular growth and allow more healthy antral follicles to grow into preovulatory size follicles that are going to be exposed to the LH surge. Compensation in ovulation rate would therefore be possible at the first cycle after surgery since Cahill \& Mauleon (1980) reported that rate of follicular growth was maximum at a follicular diameter of $0.85 \mathrm{~mm}$ in the sheep. Cahill \& Mauléon (1980) have estimated that the mean time for a follicle to grow from $0.85 \mathrm{~mm}$ to preovulatory size was $10-15$ days. Similarly, a decrease in atresia in the smallest class of antral follicles might account for the restored ovulation rates observed in subsequent cycles. The overall mean time for a follicle to pass from antrum formation $(0.21 \mathrm{~mm})$ until preovulatory size was estimated to be 44.6 days (Cahill \& Mauléon, 1980).

In the present experiment, a seasonal effect was detected in the control group over the 3 cycles studied; with advance of the breeding season, there was an increase in the population of antral follicles occurring at the expense of the preantral follicular population. The main effect of longterm unilateral ovariectomy in the present study was to maintain the number of preantral and antral follicles constant after 4 cycles. Unlike the previous study (Dufour et al., 1979), the total number of preantral and antral follicles was not increased at the 4th cycle after unilateral ovariectomy (138.5 and 140.2 respectively after 1 and 4 cycles). This discrepancy could be explained by ovulation rate differences in the two breeds used and/or by the failure to separate the confounding effects of season from that of unilateral ovariectomy. Dufour et al. (1979) used a breed of sheep $\left(\frac{3}{4}\right.$ Romanov, $\frac{1}{4}$ Préalpes-du-Sud) with a high ovulation rate (2.4 at surgery) whereas the breed used in the present study had a relatively low ovulation rate ( 1.3 at surgery). It is possible that unilateral ovariectomy of ewes with a low ovulation rate would have a slower effect on preantral follicles than was first observed with ewes with a high ovulation rate. Alternatively, since the population of follicles 70 days after unilateral ovariectomy in the previous experiment was compared to the one existing in the ovary removed at the time of first surgery, the increase in number of antral follicles might also be attributed to a seasonal effect and not only to the effect of unilateral ovariectomy.

Acute changes in the rate of atresia of antral follicles could be at least partly involved in the 
long-term within-ovary equilibrium between preantral and antral follicles. In unilaterally ovariectomized ewes, the reduction in atresia of antral follicles would reduce the need for preantral follicles to leave this phase. In contrast, in sham-operated ewes, more preantral follicles had to leave this phase to replace antral follicles that were becoming atretic. Therefore, the effect of unilateral ovariectomy, possibly mediated by an acute reduction in the rate of atresia, was to allow primordial follicles to enter a new growth wave and to establish an equilibrium between restocking of preantral from primordial follicles and depletion to antral follicles. The process of building-up of preantral follicles observed 4 cycles after unilateral ovariectomy is in agreement with the results of Cahill \& Mauléon (1980) who demonstrated that the process of re-stocking of preantral follicles from primordial follicles required about 65 days. Likewise, depletion of preantral follicles during the breeding season took place within 70 days before being statistically manifested in shamoperated ewes.

In conclusion, the acute decrease in atresia in the antral follicular population observed after unilateral ovariectomy might contribute to early and late compensation in ovulation rate. The longterm effect of unilateral ovariectomy, possibly mediated by the acute decrease in atresia, was to alter the gradual process of depletion of preantral to antral follicles occurring with the advance of the breeding season by increasing the passage of primordial follicles to preantral follicles.

We thank Mr A. Bouchard for the histological preparations and Mr D. Pitman and M. Perreault for care of the animals. Contribution No. 144.

\section{References}

Cahill, L.P. \& Mauléon, P. (1980) Influences of season, cycle and breed on follicular growth rates in sheep. $J$. Reprod. Fert. 58, 321-328.

Cahill, L.P., Mariana, J.C. \& Mauléon, P. (1979) Total follicular populations in ewes of high and low ovulation rates. J. Reprod. Fert. 55, 26-35.

Dufour, J., Cahill, L.P. \& Mauléon, P. (1979) Short- and long-term effects of hypophysectomy and unilateral ovariectomy on ovarian follicular populations in sheep. J. Reprod. Fert. 57, 301-309.
Findlay, J.K. \& Cumming, I.A. (1977) The effect of unilateral ovariectomy on plasma gonadotropin levels, estrus and ovulation rate in sheep. Biol. Reprod. 17, 178-183.

Harvey, W.R. (1960) Least squares analysis of data with unequal subclass numbers. United States Department of Agriculture, ARS-20-8 (Mimeograph).

Received 21 February 1983 